\title{
Transfer component skill deficit rates among Veterans who use wheelchairs
}

\author{
Alicia M. Koontz, PhD; ${ }^{1 *}$ Chung-Ying Tsai, PhD; ${ }^{1}$ Nathan S. Hogaboom, BS; ${ }^{1}$ Michael L. Boninger, MD $^{1-2}$ \\ ${ }^{1}$ Human Engineering Research Laboratories, Department of Veterans Affairs Pittsburgh Healthcare System, Pitts- \\ burgh, PA; and Department of Rehabilitation Science and Technology, University of Pittsburgh, Pittsburgh, PA; \\ ${ }^{2}$ Departments of Physical Medicine and Rehabilitation and Bioengineering, University of Pittsburgh, Pittsburgh, PA
}

\begin{abstract}
The purpose of this study was to quantify the deficit rates for transfer component skills in a Veteran cohort and explore the relationship between deficit rates and subject characteristics. Seventy-four men and 18 women performed up to four transfers independently from their wheelchair to a mat table while a therapist evaluated their transfer techniques using the Transfer Assessment Instrument. The highest deficit rates concerned the improper use of handgrips (63\%). Other common problems included not setting the wheelchair up at the proper angle $(50 \%)$ and not removing the armrest $(58 \%)$. Veterans over $60 \mathrm{yr}$ old and Veterans with moderate shoulder pain were more likely to set up their wheelchairs inappropriately than younger Veterans $(p=0.003)$ and Veterans with mild shoulder pain $(p=0.004)$. Women were less likely to remove their armrests than men $(p=0.03)$. Subjects with disabilities other than spinal cord injury were less inclined to set themselves up for a safe and easy transfer than the subjects with spinal cord injury $(p</=0.001)$. The results provide insight into the disparities present in transfer skills among Veterans and will inform the development of future transfer training programs both within and outside of the Department of Veterans Affairs.
\end{abstract}

Key words: activities of daily living, clinical practice guideline, clinical practice variations, healthcare disparities, patient outcome assessment, repetitive strain injury, shoulder, spinal cord injury, training, upper limb.

\section{INTRODUCTION}

Transfers have been ranked as one of the most essential wheelchair skills for daily living [1], and independence with transfers is one of the most important determinants for community participation and quality of life [2]. A full-time wheelchair user usually performs 15 to 20 transfers each day [3]. Performing transfers is essential for completing tasks of daily living (e.g., bathing, toileting, and driving) and for enabling participation in a wide variety of public settings (e.g., restaurants, parks, pools, medical facilities) and recreational activities (e.g., handcycling, skiing, rugby). Possessing the ability to transfer independently therefore promotes autonomy and participation in many areas of life.

\footnotetext{
Abbreviations: $\mathrm{L}=$ lumbar, NDVWSC $=$ National Disabled Veterans Winter Sports Clinic, NRS = numerical rating scale, $\mathrm{NVWG}=$ National Veterans Wheelchair Games, $\mathrm{SCI}=$ spinal cord injury, $\mathrm{T}=$ thoracic, TAI $=$ Transfer Assessment Instrument, TBI = traumatic brain injury, VA $=$ Department of Veterans Affairs.

*Address all correspondence to Alicia M. Koontz, PhD; Human Engineering Research Laboratories, 6425 Penn Ave, Suite 400, Pittsburgh, PA 15206; 412-822-3700. Email: akoontz@pitt.edu http://dx.doi.org/10.1682/JRRD.2015.02.0023
} 
Transfers are one of the most strenuous wheelchairrelated activities [4]. Transfers, along with wheelchair propulsion and weight-relief raises, predispose wheelchair users to developing upper-limb pain and overuserelated injuries [5-11]. Research has shown that between 31 and 73 percent of civilians with spinal cord injuries (SCIs) report shoulder pain $[8,12-13]$. The incidence of shoulder pain is around 70 percent [14] for Veterans with paraplegia and 80 percent among Veterans with tetraplegia [15]. The prevalence and intensity of shoulder pain in these studies involving Veterans were not associated with the age of the Veteran and only moderately associated with the duration of wheelchair use. Another study found that 80 percent of Veterans with lower-limb amputations had median neuropathy across both wrists, and 70 percent had ulnar nerve entrapment across elbows that was attributed to the improper fit of assistive devices and overuse injuries [16]. With the onset of pain or injury, wheelchair users may begin to withdraw from community participation, become dependent on others, functionally decline, and require more medical care and expenditures [2,5].

Only about half of the Veterans with SCI with shoulder pain report seeking treatment for their pain [15]. Individuals who seek attention tend to use conservative treatments in an attempt to alleviate the pain and are generally unsuccessful $[8,10]$. Surgical treatments for upperlimb problems have not fared well because individuals are unable to rest their limbs to allow ample time for soft tissues to heal [11]. Moreover, upper-limb assistive devices for transfers, such as sliding boards and lifts, appear to be an unused option for the treatment and prevention of shoulder problems because of their inconvenience and lack of portability $[1,8,17]$. For these reasons, education and training on proper transfer techniques may be paramount to preserving limb function and maximizing quality of life, independence, and participation [5,18-20].

The amount and quality of education and training on transfer skills that a person receives varies widely [2122]. About 42 percent of wheelchair users claimed to have learned essential mobility skills from a professional, while the remaining users either never learned them (3\%), learned them on their own after their initial rehabilitation stay $(42 \%)$, or learned them from a peer $(13 \%)$ [1]. Clinical practice recommendations concerning best transfer practices have been published [23] but have not been well disseminated into clinics [1]. Transfer techniques taught to patients during rehabilitation have been largely based on general guidelines and practices found in textbooks [24-26]. Moreover, until recently there has been no tool that enables clinicians to evaluate transfer technique in detail. The Transfer Assessment Instrument (TAI) was developed to fill this void in the field. The TAI is a 27 -item construct that a clinician can use to quantify their patients' transfer skills and identify areas to focus training of proper technique [22,27]. The overall TAI score is a measure of transfer "quality," and higher scores reflect better adherence with "best" evidence-based transfer technique and practices.

Given that the incidence of upper-limb pain is high among Veterans, that there is no standard of care concerning formal assessment of technique, and that the amount and quality of transfer skill training a Veteran receives is unknown, we sought to (1) use the TAI to evaluate and quantify the deficit rates for transfer component skills among Veterans and (2) explore the relationships between transfer skills and Veteran characteristics such as weight, upper-limb pain, sex, and type and duration of disability. Understanding the deficits in transfer skills and their associations with sociodemographic factors will help guide the development of future transfer technique training and educational programs both within and outside of the Department of Veterans Affairs (VA).

\section{METHODS}

\section{Participants}

Subjects were recruited from the National Disabled Veterans Winter Sports Clinic (NDVWSC) in Snowmass Village, Colorado, in 2011; the National Veterans Wheelchair Games (NVWG) in Richmond, Virginia, in 2012; and the NVWG in Tampa, Florida, in 2013. All the subjects signed a consent form approved by the VA Pittsburgh Healthcare System Institutional Review Board before testing. Subjects needed to meet the following inclusion criteria to participate in the study: wheelchair use for at least $1 \mathrm{yr}$, ability to sit upright for at least $4 \mathrm{~h} / \mathrm{d}$, age over $18 \mathrm{yr}$, wheelchair use at least $40 \mathrm{~h} / \mathrm{wk}$, and English speaking. The exclusion criteria were (1) current or recent history of pressure sores in the last year and (2) ability to stand without support.

\section{Testing Protocol}

Prior to testing, subjects' demographic data, such as self-reported age, weight, type of disability, date of injury 
or diagnosis, and wheelchair type, were collected. Subjects' average shoulder pain in the past week was also recorded using the numerical rating scale (NRS) [28], which scores pain from 0 to 10 . A 0 implies no pain, and 10 is the worst pain imaginable. Participants were then asked to perform up to four transfer trials to and from a height-adjustable mat table using their habitual approaches. The height of the mat table was purposefully set to be 2 in. higher than their wheelchair seat to floor height. They were then told they could position their wheelchairs and change the height of the mat table based on their personal preferences. During each transfer, a physical therapist who was trained to use the TAI evaluated subjects' transfer skills using TAI 3.0 [27]. The same therapist performed the transfer evaluations at all three Veterans' events. The subdomains of the TAI are (1) preparing for the transfer (e.g., setup of the wheelchair with respect to the target surface), (2) use of conservation techniques (e.g., alternating leading/trailing arm, using handgrips when appropriate), and (3) quality of the transfer (e.g., smooth and controlled, impingement positions are avoided during extreme weight-bearing). Items were derived from biomechanical and ergonomic principles that minimize joint loading $[5,24]$. A highly scored transfer lowers the risk of injury by decreasing forces at the shoulders and minimizing awkward positions [29]. The TAI takes less than $10 \mathrm{~min}$ to complete and requires no specialized equipment or testing tools [21]. The scale has been rigorously tested for validity and reliability $[21,27,29]$.

\section{Data Analysis}

\section{Transfer Assessment Instrument Scores}

Part 1 contains 15 items that allow for scoring specific issues concerning the transfer process such as "does the individual bring his/her wheelchair within 3 in. of the surface" and "does he/she put feet and hands in a stable position." Each item in part 1 is scored a "yes," "no," or "not applicable." A "yes" score yields a numerical value of 1 , a "no" score yields a numerical value of 0 , and "not applicable" items are removed from the data set. An averaged trial score is calculated to represent each subject's final item score. For example, if the subject performed four transfer trials and his or her item 7 scores in part 1 are two "yes" and two "no," a 0.5 (which is $(1+1+0+$ $0) / 4=0.5$ ) will be his or her final item 7 score. Therefore, all possible final item scores for each item in part 1 are 0 (all "no" in the four trials), 0.25 (one "yes" and three "no"), 0.5 (half "yes" and half "no"), 0.75 (three "yes" and one "no"), and 1 (all "yes" in the four trials). The part 1 score is the summation of all the applicable final item scores, multiplied by 10 and divided by the total number of applicable items. The total part 1 score ranges from 0 to 10 . For example, if there were 7 applicable items in part 1 and the final item scores are $0,0,1$, $0.5,1,0.5$, and 1 , the total part 1 score will be $5.71([(0+$ $0+1+0.5+1+0.5+1) \times 10] / 7=5.71)$.

Part 2 consists of 12 items and evaluates the global performance of transfer quality, techniques, and indication of assistance. The items in part 2 are scored on a Likert scale ranging from 0 to 4 and are based on all the transfers trials. A 0 on each part 2 item means that the rater strongly disagrees with the subject's ideal performance for this item, and a 4 means strongly agree. The part 2 score is the summation of all the item scores in part 2 , multiplied by 2.5 and divided by the total number of applicable items. The part 2 score also ranges from 0 to 10. The final TAI score is the average of the part 1 and part 2 scores and ranges from 0 to 10 .

\section{Descriptive Analysis of Transfer Deficits}

To describe the general deficits in transfer technique, a descriptive analysis was performed on the TAI item scores for all the Veterans who participated in this study across the three venues $(n=92)$. To simplify the analysis, for each item in part 1 , subjects who performed the transfer skill properly for half or less than half of the transfer trials (scored a $0,0.25$, and 0.50 ) were placed in one group while subjects who performed the transfer skill in all or most of the transfer trials (scored a 0.75 or 1 ) were placed in a separate group. Similarly, for each item in part 2, subjects who did not globally meet the performance criteria for a particular skill area (scored a 0,1 , or 2 ) were placed in one group while subjects who did globally meet performance criteria for a particular skill area (scored a 4 or 5) were placed in a separate group. The percentages of subjects who met or did not meet the performance criteria for each transfer skill (e.g., TAI item) according to these definitions were computed.

\section{Relationship Between Transfer Skills and Veteran Characteristics}

Categories were formed for each demographic variable, including sex (male/female); type of disability (tetraplegia, high paraplegia [thoracic (T)1 to T7], low 
paraplegia [T8 to lumbar (L)4] [30]); and others including multiple sclerosis, brain injury, Guillain-Barre syndrome, transfemoral amputation, and post-polio), time since injury or diagnosis $(\leq 10 \mathrm{yr},>10$ but $\leq 20 \mathrm{yr}$, and $>20 \mathrm{yr}$ ), age ( $<40 \mathrm{yr},>40$ but $<60 \mathrm{yr}$, and $>60 \mathrm{yr}$ of age), weight (40-80 kg or $>80 \mathrm{~kg}$ ), and shoulder pain (no shoulder pain when NRS score was 0 , mild shoulder pain for NRS scores that ranged from 1 to 4 , and more than moderate shoulder pain for NRS scores that ranged from 5 to 10 [31]). For each demographic variable, the Veteran was assigned to one of the categories, and his or her final TAI scores were compared across the categories using either a Mann-Whitney test or Kruskal-Wallis test. Nonparametric tests were chosen for this analysis because some of the TAI final scores in the subgroups were not normally distributed. TAI items by which at least 30 percent of the Veterans did not perform the skill correctly on part 1 and part 2 were identified. For each demographic variable, the Veterans who did and did not perform that skill correctly were categorized into groups and compared using a chi-square test. If the test was significant and there were more than two subgroups in a category, such as age and type of disability, additional chi-square tests with a Bonferonni correction for the $p$-value were used to determine the specific subgroups that were significantly different from each other. The $\alpha$ value for these analyses was set at 0.05 . The $\alpha$ value for post hoc tests for type of disability was set to $0.0125(0.05 / 4)$. The $\alpha$ value for the post hoc tests for time since injury or diagnosis, shoulder pain, and age was set at $0.017(0.05 / 3)$. All statistical analysis was performed using SPSS 20.0 software (IBM Corporation; Armonk, New York).

\section{RESULTS}

\section{Subjects}

Forty-one subjects at the NDVWSC in 2011, 26 subjects at the NVWG in 2012, and 25 subjects at the NVWG in 2013 participated in the study. The sample consisted of mostly men and Veterans with an SCI (Table 1). Seventeen of the Veterans used power wheelchairs (18.5\%), and 75 Veterans used manual wheelchairs (81.5\%). One subject's type of disability, six subjects' date of diagnosis, and two subjects' weight were not reported.

\section{Transfer Component Skill Deficit Rates}

The component skills with the highest deficit rates were handgrips used by the leading (part 1, item 9) and trailing (part 1, item 10) arms (Table 2). The next most common problem areas concerned proper body and wheelchair positioning prior to the transfer. Half of the Veterans $(50 \%)$ did not set their wheelchair up at the proper angle next to the mat table (part 1, item 2), 31 percent did not position their wheelchair to make it easier to transfer forward of the rear wheel (part 1, item 3), 58 percent did not remove a removable armrest (part 1, item 4), 36 percent did not attempt to change the height of the mat table to enable a level transfer (part 1, item 5), and 38 percent did not place their feet in a stable position before the transfer (part 1, item 6). During the lifting and pivoting phase of transfer, 47 percent of Veterans did not

Table 1.

Number (\%) of subjects in each demographic category.

\begin{tabular}{|c|c|}
\hline Characteristic & n (\% sample) \\
\hline \multicolumn{2}{|l|}{$\overline{\text { Sex }}$} \\
\hline Male & $74(80)$ \\
\hline Female & $18(20)$ \\
\hline \multicolumn{2}{|l|}{ Type of Disability } \\
\hline Tetraplegia & $26(29)$ \\
\hline High Paraplegia (T1-T7) & $22(24)$ \\
\hline Low Paraplegia (T8-L4) & $31(34)$ \\
\hline $\begin{array}{l}\text { Others (MS, brain injury, GBS, } \\
\text { TFA, post-polio) }\end{array}$ & $12(13)$ \\
\hline \multicolumn{2}{|l|}{ Time Since Injury or Diagnosis, yr ${ }^{*}$} \\
\hline$\leq 10$ & $39(45)$ \\
\hline $10-20$ & $25(29)$ \\
\hline$>20$ & $22(26)$ \\
\hline \multicolumn{2}{|l|}{ Shoulder Pain ${ }^{\dagger}$} \\
\hline None $(\mathrm{NRS}=0)$ & $28(30)$ \\
\hline Mild (NRS = 1-4) & $46(50)$ \\
\hline More than Moderate (NRS $=5-10)$ & $18(20)$ \\
\hline \multicolumn{2}{|l|}{ Age, $\mathrm{yr}^{+}$} \\
\hline $20-50$ & $46(50)$ \\
\hline $51-60$ & $26(28)$ \\
\hline$>60$ & $20(22)$ \\
\hline \multicolumn{2}{|l|}{ Weight, kg ${ }^{\S}$} \\
\hline $40-80$ & $52(58)$ \\
\hline 80 & $38(42)$ \\
\hline \multicolumn{2}{|c|}{$\begin{array}{l}{ }^{*} \text { mean }=14.46 \pm 10.45, \text { range: } 1.0-43.5 . \\
{ }^{\dagger} \text { mean }=2.4 \pm 2.5, \text { range: } 0-9 . \\
{ }^{\dagger} \text { mean }=49.1 \pm 12.2, \text { range: } 22-75 . \\
{ }_{\text {}} \text { mean }=79.0 \pm 17.5 \text {, range: } 30.3-122.3 . \\
\text { GBS = Guillain-Barre syndrome, } \mathrm{L}=\text { lumbar, MS = multiple sclerosis, NRS = } \\
\text { numeric rating scale }(1-10), \mathrm{T}=\text { thoracic, TFA = transfemoral amputation. }\end{array}$} \\
\hline
\end{tabular}


Table 2.

Number (\%) of Veterans who performed transfer skills incorrectly and correctly.

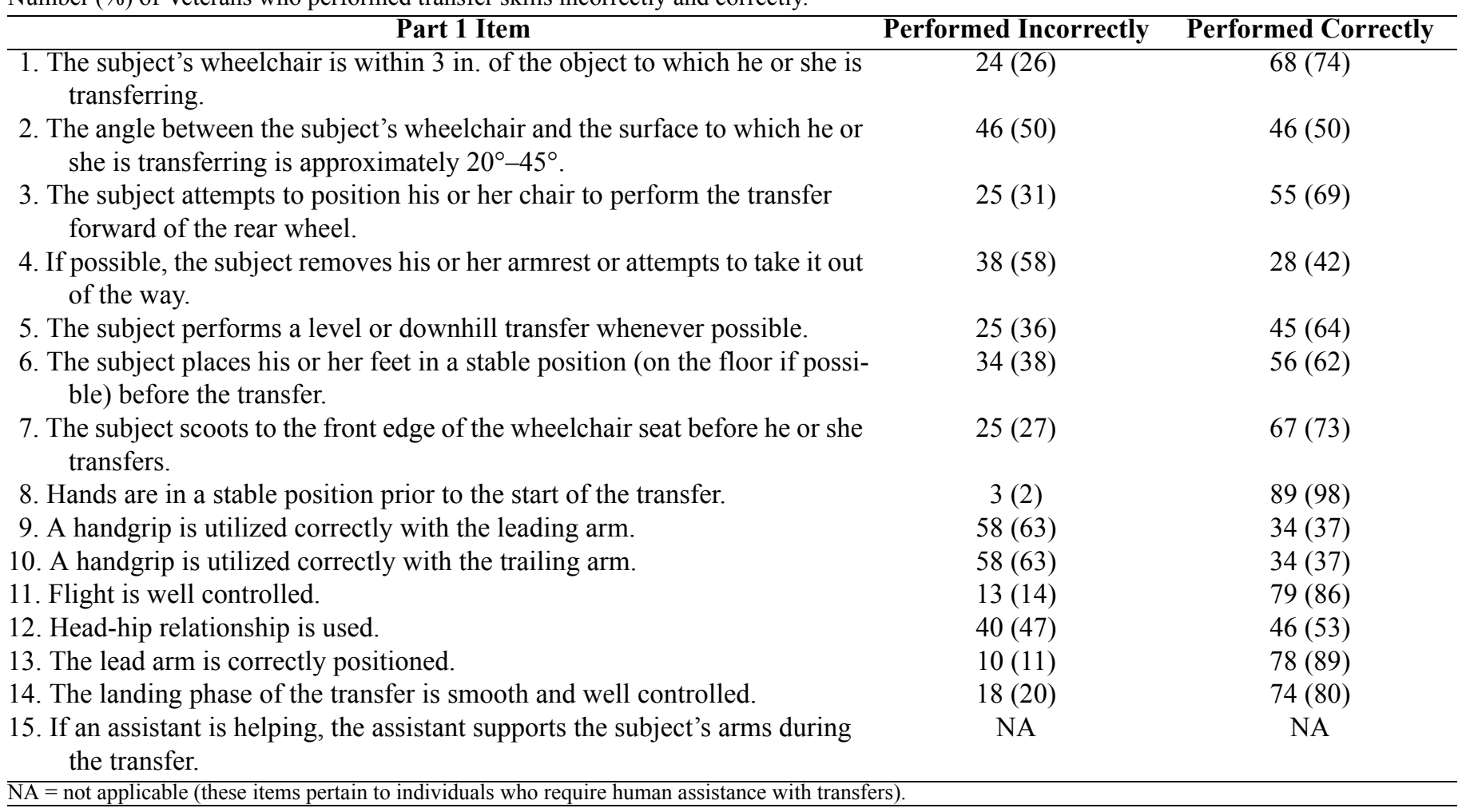

use the head-hips technique correctly (part 1, item 12). Almost all of the Veterans $(98 \%)$ placed their hands in a stable position prior to the start of the transfer (part 1, item 8), and 80 percent or more exhibited smooth and controlled movements during the lift-pivot phase of the transfer process (part 1, item 11) and during landing (part 1, item 14). A high percentage of Veterans (89\%) positioned their lead arm correctly (part 1, item 13).

Globally, the highest failure rates were again related to inappropriate handgrips (part 2, item 5) and not setting oneself up for a safe transfer (part 2, item 2), followed by not attempting to change the mat table height to make the transfer level (part 2, item 3), not getting close enough to the mat surface (part 2, item 4), and not exhibiting smooth and controlled transfer movements (part 2, item 8) (Table 3). The Veterans globally positioned their lead arm well during the weight-bearing portion of the transfer (part 2, item 1), used a transfer aid when necessary (part 2, item 6), and attempted to alternate leading and trailing arms over the course of assessment (part 2, item 7).

The average final TAI score for the transfers was $7.41 \pm 1.33$, with scores that ranged from 3.21 to 10 . There was no significant difference in TAI final scores between women and men, different types of disabilities, levels of shoulder pain, length of time after injury or diagnosis, age, and weight (Table 4).

Older Veterans (over $60 \mathrm{yr}$ old) and Veterans who had more than a moderate amount of shoulder pain were more likely to set up their wheelchairs at an inappropriate angle next to the transfer surface than younger Veterans (under $40 \mathrm{yr}$ old) $(p=0.003)$ and Veterans with mild shoulder pain (part 1, item 2) ( $p=0.004)$ (Tables 5-6). Women were less likely to remove their armrests prior to making the transfer (part 1 , item 4$)$ than men $(p=0.03)$. Veterans with disabilities other than SCI were more inclined to perform an uphill transfer (e.g., not adjust the mat table height so that they could perform a level or downhill transfer (item 5 in part 1 and item 3 in part 2, $p<$ 0.004). Subjects with high and low paraplegia were less likely to use correct handgrips (items 9 and 10 in part 1 and item 5 in part 2) than subjects with other types of disabilities $(p \leq 0.006)$. Compared with subjects with SCI, subjects with other types of disabilities were less inclined to set themselves up for a safe and easy transfer (part 2, item 2) $(p \leq 0.001)$. There was no significant association 
JRRD, Volume 53, Number 2, 2016

Table 3.

Number (\%) of Veterans who globally did or did not meet given performance criteria.

\section{Part 2 Item}

$\begin{array}{cc}\text { Did Not } & \text { Globally Met } \\ \text { Globally Meet } & \text { Performance Criteria } \\ \text { Performance Criteria } & \end{array}$

1. The lead arm is positioned correctly during the weight bearing portion of the transfer.

2. The subject sets him or herself up for a safe and easy transfer.

3. The subject attempts to change the height of the object he or she is transferring to/from to make the transfer level.

4. The subject gets close to the object that he or she is transferring onto.

5. The subject uses handgrips when necessary. $6(7)$ $82(93)$

$50(54)$

$24(34)$

$21(23)$

$62(67)$

8 (9)

2 (3)

21 (23)

NA

NA

NA

NA
42 (46)

46 (66)

71 (77)

30 (33)

84 (91)

77 (97)

71 (77)

NA

NA

NA

NA

12. The subject is able to correctly direct his or her care in an assertive and polite manner.

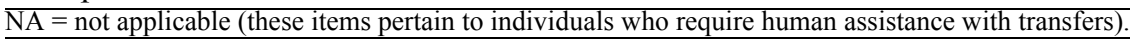

\section{Table 4.}

Transfer Assessment Instrument final scores (mean \pm standard deviation) for each group, type of statistics used to compare scores across groups, and $p$-values.

\begin{tabular}{|c|c|c|c|}
\hline Group & Final Score & Statistic & $p$-Value \\
\hline$\overline{\operatorname{Sex}}$ & & Mann-Whitney U test & 0.55 \\
\hline Female, $n=18$ & $7.59 \pm 1.21$ & & \\
\hline Tetraplegia, $n=26$ & $7.56 \pm 1.43$ & & \\
\hline High Paraplegia, $n=22$ & $7.41 \pm 1.23$ & & \\
\hline Shoulder Pain & & Kruskal-Wallis test & 0.56 \\
\hline None $(\mathrm{NRS}=0), n=28$ & $7.45 \pm 1.34$ & & \\
\hline Mild $(\mathrm{NRS}=1-4), n=46$ & $7.47 \pm 1.42$ & & \\
\hline More than Moderate $(\mathrm{NRS}=5-10), n=18$ & $7.22 \pm 1.12$ & & \\
\hline Time, yr & & Kruskal-Wallis test & 0.51 \\
\hline$<40, n=16$ & $8.36 \pm 1.07$ & & \\
\hline $40-60, n=56$ & $7.23 \pm 1.30$ & & \\
\hline$>60, n=20$ & $7.43 \pm 1.08$ & & \\
\hline Weight, kg & & Mann-Whitney U test & 0.54 \\
\hline $40-80$ & $7.32 \pm 1.47$ & & \\
\hline$>80$ & $7.60 \pm 1.12$ & & \\
\hline
\end{tabular}


Table 5.

Number (\%) of Veterans with certain demographic characteristics who performed each part 1 item skill correctly and incorrectly.

\begin{tabular}{|c|c|c|c|c|c|}
\hline \multirow[t]{2}{*}{ Item } & \multicolumn{2}{|c|}{$\begin{array}{l}\text { Performs Skill in Half or Less } \\
\text { Than Half of }(\leq 2) \text { Trials }\end{array}$} & \multicolumn{2}{|c|}{$\begin{array}{l}\text { Performs Skill in All or Most of } \\
\qquad(>2) \text { Trials }\end{array}$} & \multirow[t]{2}{*}{ Statistic } \\
\hline & $n$ & $\%$ & $n$ & $\%$ & \\
\hline \multicolumn{6}{|l|}{$\overline{\text { Item } 2}$} \\
\hline \multicolumn{6}{|l|}{ Age, yr } \\
\hline$<40$ & 3 & 19 & 13 & 81 & - \\
\hline $40-60$ & 29 & 52 & 27 & 48 & - \\
\hline$>60$ & 14 & 70 & 6 & 30 & - \\
\hline$X^{2}(2)$ & - & - & - & - & 9.52 \\
\hline$p$-Value & - & - & - & - & 0.007 \\
\hline Post hoc $p$-value, age $<40$ vs $>60$ & - & - & - & - & 0.003 \\
\hline \multicolumn{6}{|l|}{ Shoulder Pain } \\
\hline None & 13 & 48 & 14 & 52 & - \\
\hline Mild & 17 & 38 & 28 & 62 & - \\
\hline More than Moderate & 14 & 78 & 4 & 22 & - \\
\hline$X^{2}(2)$ & - & - & - & - & 8.24 \\
\hline$p$-Value & - & - & - & - & 0.02 \\
\hline $\begin{array}{l}\text { Post hoc } p \text {-value, mild vs more than } \\
\text { moderate }\end{array}$ & - & - & - & - & 0.004 \\
\hline \multicolumn{6}{|l|}{ Item 4} \\
\hline \multicolumn{6}{|l|}{ Sex } \\
\hline Male & 27 & 51 & 26 & 49 & - \\
\hline Female & 11 & 85 & 2 & 15 & - \\
\hline$X^{2}(1)$ & - & - & - & - & 4.85 \\
\hline$p$-Value & - & - & - & - & 0.03 \\
\hline \multicolumn{6}{|l|}{ Item 5} \\
\hline \multicolumn{6}{|l|}{ Paralysis Level } \\
\hline Tetraplegia & 3 & 18 & 14 & 82 & - \\
\hline High Paraplegia & 5 & 29 & 12 & 71 & - \\
\hline Low Paraplegia & 8 & 33 & 16 & 67 & - \\
\hline Other & 8 & 73 & 3 & 27 & - \\
\hline$X^{2}(3)$ & - & - & - & - & 9.42 \\
\hline$p$-Value & - & - & - & - & 0.02 \\
\hline Post hoc $p$-value, tetraplegia vs other & - & - & - & - & 0.004 \\
\hline \multicolumn{6}{|l|}{ Item 9} \\
\hline \multicolumn{6}{|l|}{ Paralysis Level } \\
\hline Tetraplegia & 14 & 58 & 10 & 42 & - \\
\hline High Paraplegia & 18 & 78 & 5 & 22 & - \\
\hline Low Paraplegia & 24 & 73 & 9 & 27 & - \\
\hline Other & 2 & 18 & 9 & 82 & - \\
\hline$X^{2}(3)$ & - & - & - & - & 13.43 \\
\hline$p$-Value & - & - & - & - & $<0.01$ \\
\hline Post hoc $p$-value, high paraplegia vs other & - & - & - & - & 0.001 \\
\hline Post hoc $p$-value, low paraplegia vs other & - & - & - & - & 0.001 \\
\hline \multicolumn{6}{|l|}{ Item 10} \\
\hline \multicolumn{6}{|l|}{ Paralysis Level } \\
\hline Tetraplegia & 14 & 58 & 10 & 42 & - \\
\hline High Paraplegia & 18 & 78 & 5 & 22 & - \\
\hline
\end{tabular}


JRRD, Volume 53, Number 2, 2016

Table 5. (cont)

Number (\%) of Veterans with certain demographic characteristics who performed each part 1 item skill correctly and incorrectly.

\begin{tabular}{|c|c|c|c|c|c|}
\hline \multirow[t]{2}{*}{ Item } & \multicolumn{2}{|c|}{$\begin{array}{c}\text { Performs Skill in Half or Less } \\
\text { Than Half of }(\leq 2) \text { Trials }\end{array}$} & \multicolumn{2}{|c|}{$\begin{array}{l}\text { Performs Skill in All or Most of } \\
\qquad(>2) \text { Trials }\end{array}$} & \multirow[t]{2}{*}{ Statistic } \\
\hline & $n$ & $\%$ & $n$ & $\%$ & \\
\hline Low Paraplegia & 25 & 76 & 8 & 24 & - \\
\hline Other & 1 & 9 & 10 & 91 & - \\
\hline$X^{2}(3)$ & - & - & - & - & 18.68 \\
\hline$p$-Value & - & - & - & - & $<0.01$ \\
\hline Post hoc $p$-value, high paraplegia vs other & - & - & - & - & $<0.001$ \\
\hline Post hoc $p$-value, low paraplegia vs other & - & - & - & - & $<0.001$ \\
\hline
\end{tabular}

Table 6.

Number (\%) of Veterans with certain demographic characteristics who performed each part 2 item skill correctly and incorrectly.

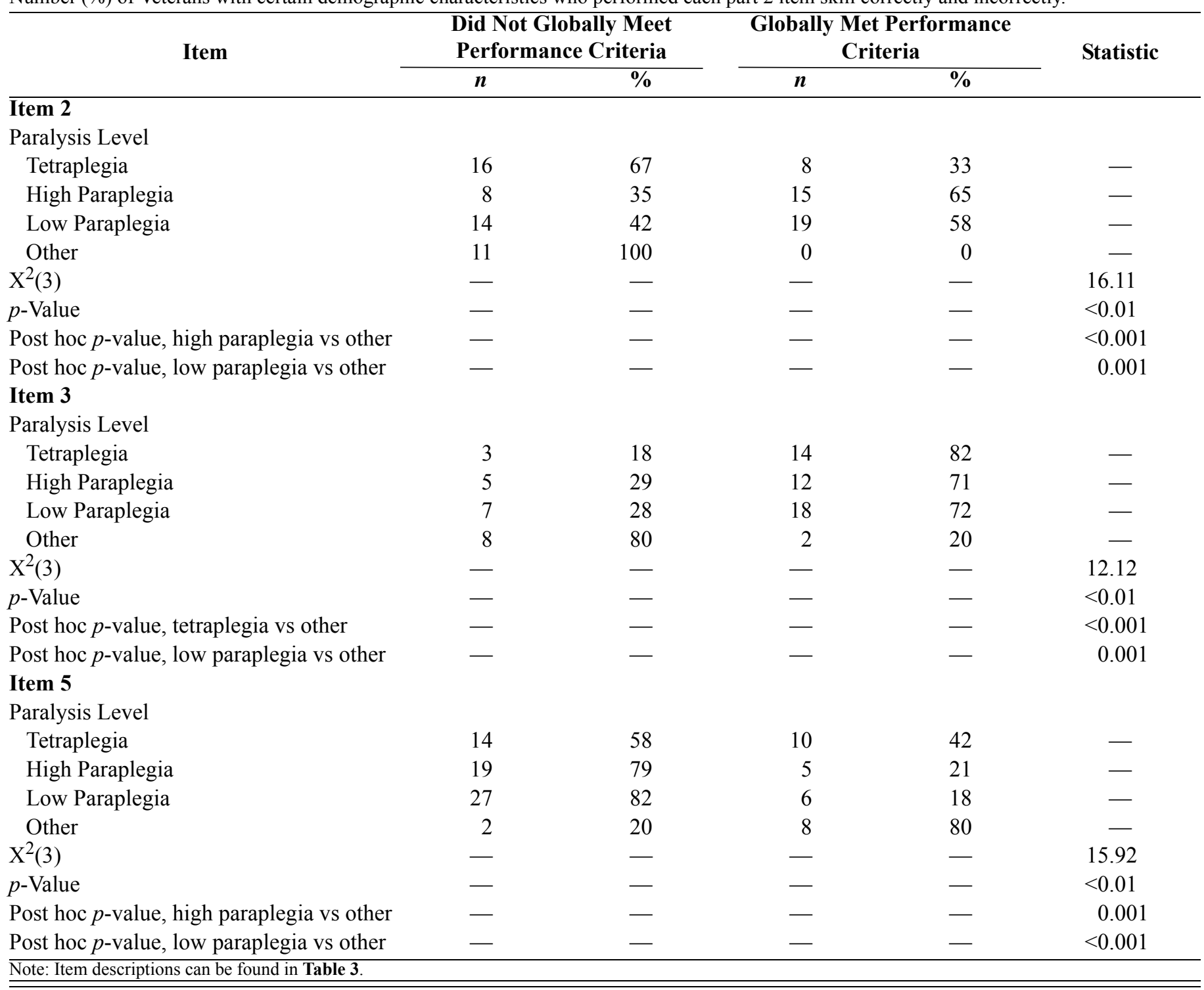


found between performing skills correctly and subjects' weight $(p \geq 0.08)$ and time since diagnosis or injury ( $p \geq$ $0.16)$.

\section{DISCUSSION}

Using proper transfer skills may protect wheelchair users from developing upper-limb pain and injuries and extend their participation in home and community activities [2,32]. Although every Veteran in this study could transfer independently to the mat table and was successful with making the transfer, many of them used techniques that were inconsistent with the TAI skill set. Based on the failure rates found in this study, there is much room for improvement, signaling a need for further education and a standardized approach for learning how to perform high-quality transfers.

\section{Transfer Skill Deficits}

The specific skills lacking most in these Veterans (e.g., greater than a $30 \%$ failure rate) related to proper positioning of the wheelchair next to the target surface, armrest removal, not placing the feet in a stable position on the floor, not attempting to make the target surface level with their wheelchair, incorrect use of handgrip, and the use of the head-hip relationship technique.

Appropriately setting up the wheelchair (and body) is an important first step of the transfer process. The TAI checks that wheelchairs are placed as close as possible to the target surface (within 3 in.) (part 1, item 1) and are positioned at an angle between $20^{\circ}$ and $45^{\circ}$ (part 1, item 2 ) with respect to the transfer target. This position, combined with scooting forward in the wheelchair (part 1, item 3), provides space for the buttocks to pivot during the transfer [33] and helps manual wheelchair users clear their buttocks of the rear wheels, which extend above the wheelchair seat cushion. Angling the wheelchair in this manner has also been shown to lower shoulder internal rotation moment [29], which may help to prevent shoulder impingement syndrome [34]. Removing the armrest on the transfer side (part 1, item 4) is also important because the armrest can impede the transfer, requiring more effort and awkward movements to pivot the buttocks around or over the armrest.

Placing the feet on the floor in a stable position, typically midway between the start and end position of the transfer, is recommended because the legs can be used to support a considerable amount of body weight (around $30 \%$ ), which offloads the amount of loading on the upper limbs [4]. Studies have also found that lower-limb fractures, especially below the knee at the distal tibia and fibia, are common among people with SCI and occur often during transfers [35-36]. Thus, proper feet and leg positioning is important for reducing upper-limb loading and lowering the risk for lower-limb fractures during transfers.

Performing level transfers when possible is important for decreasing muscle effort and the forces borne by the upper limbs [37-38]. In this study, subjects were made aware that the mat table was height adjustable and could set the mat height according to their preferences. However, 36 percent of the subjects chose not to adjust the height of the mat table to be level with their wheelchair seats. This could be because they did not know that making level transfers reduces forces on the upper limbs or because performing nonlevel transfers is not "difficult" for them and they performed these types of transfers routinely within and outside of the home.

The skills with the highest failure rate occurred for the two items that evaluate appropriate use of handgrips by the leading and trailing hands (part 1, items 9 and 10). Clinical practice guidelines encourage wheelchair users to use handgrips instead of flat hands or fists when performing transfers [23]. Using flat hands during transfers will cause extreme wrist extension, which is known to increase the pressure in the carpal tunnel and is a factor identified in the etiology of carpal tunnel syndrome [3940]. A closed-finger fist will result in excessive pressure on the metacarpal joints [41]. Using a proper grip can provide better overall stability for transfers than a closedfinger fist and prevent excessive pressure on the metacarpal joints and extreme wrist extension [23].

This group of Veterans was also deficient with respect to the skill of using a head-hips relationship. This skill involves leaning the trunk forward to generate enough momentum to lift and rotate the buttocks up and over to the target surface [42]. Multiple studies have shown that using this skill may reduce shoulder forces and recruit larger muscle groups around the shoulders $[3,43]$. More recently, this skill was also found to be more dynamically stable and resilient to external disturbances compared with transferring with the trunk in a more upright posture [44].

Transfer quality, measured using TAI scores, has been shown to influence the biomechanics of performing 
a wheelchair transfer [29]. More specifically, lower scores on the TAI were associated with increases in forces, moments, and the rates of loading at the wrists, elbows, and shoulders. Many of the same skills that these Veterans were lacking have been directly linked with awkward motions and higher forces and moments $[29,44-45]$. These skill deficits combined with the repetitious nature of transfers (upward of 40 times per day [4]) may help explain why the prevalence of upper-limb pain and injuries are so high among Veterans with SCI [14-15].

Possible explanations for the failure rates in transfer skills observed in this study include a lack of time or emphasis on patient education and teaching wheelchair and transfer skills during initial rehabilitation stays, insufficient follow-up on these skills during outpatient rehabilitation visits, or a lack of knowledge among clinicians about proper transfer techniques and how to teach them to patients $[1,46]$. Another challenge relates to teaching transfer skills to newly spinal cord-injured patients who need to work first on regaining the strength necessary to support their body weight with their arms and build endurance so that they can perform independent transfers successfully after they have fully recovered. It has been suggested that technology be developed to promote partial weight-bearing support during transfers so that newly spinal cord-injured patients can learn the skills without having to rely on their physical capacity to carry out the transfer on their own [4].

\section{Relationship Between Subjects' Characteristics And Transfer Skills}

Older Veterans were less likely to set up an appropriate angle between their wheelchairs and the transfer surface. Because of the expansion of research on upper-limb pain and injuries among wheelchair users just over the last decade and the availability of practice guidelines for clinicians and patients related to wheelchair use, it is possible that many of the older Veterans tested who had been living a longer time with a disability did not receive evidence-based mobility skills training during their initial rehabilitation stay. Or the older Veterans who acquired a disability later in their life also had to deal with agerelated health issues (e.g., increased muscle weakness and comorbidities like diabetes, cardiovascular diseases, and arthritis), which may have delayed the rehabilitation process and lowered the priority of learning transfer skills. Veterans with higher levels of shoulder pain were also less likely to set up their wheelchairs at the correct angle than Veterans with less pain. As noted earlier, setting the wheelchair up at the proper angle has been associated with protective biomechanical markers (e.g., reduced shoulder internal rotation moments) [29].

Women Veterans were less likely to remove their armrest than men. It may be that instead of removing the armrest they chose to set their wheelchairs up at an angle that minimized the need to remove the armrest or that they scooted forward in the seat to avoid impacting the armrest. Wheelchair positioning and scooting forward are items scored separately on the TAI. Only 49 percent of the men in the study, compared with 15 percent of women, removed their armrests, indicating that for both men and women this is a component skill that needs to be emphasized during transfer training.

The results of the study showed that Veterans with paraplegia were more likely to set themselves up for a safe and easy transfer than Veterans with other types of disabilities. The other types of disabilities represented in this study included Veterans with progressive diseases (e.g., multiple sclerosis and Guillain-Barre syndrome), traumatic injuries (traumatic brain injury [TBI] and amputation) and post-polio. It is possible that transfer training for Veterans occurs more frequently in acute SCI rehabilitation than for Veterans with progressive diseases or those with amputation and TBI. Veterans with low paraplegia (injury level ranges from T8 to L4 [30]) and tetraplegia were more likely than Veterans with other disabilities to set themselves up for a level transfer. Because these individuals have reduced trunk control and persons with tetraplegia lack triceps and handgrip function, transfers to higher and even lower surfaces are much more difficult [47]. Having a more limited capacity to perform nonlevel transfers may explain why the Veterans with low paraplegia and tetraplegia chose to make the mat table level with their wheelchair first prior to performing the transfer.

The Veterans with SCI in our study were less likely to use a proper handgrip than persons with other disabilities. This skill may be less intuitive than some of the other skills like scooting forward to the front of the wheelchair or putting hands in a stable position prior to starting the transfer. More commonly, we observed that individuals placed the hand and palm flat on the mat table with their fingers extended or in the form of a fist placed directly onto the surface. While a fist places the wrist in a more neutral position, the metacarpal joints were not designed to withstand the high weight-bearing forces of a 
transfer $[23,39-40]$. Ideally, the hand should drape over the edge of the surface with fingers actively flexed when possible (e.g., actively gripping the edge of the mat table) [23]. Veterans could also score a "no" on this item if they reached too far outside their base of support to attain a handgrip. Knowing where best to place the hands relative to the body is a skill that is very important for reducing forces and effort $[29,45]$.

The reason that more Veterans with SCI did not use good handgrips compared with Veterans with other disabilities is not clear. Because Veterans with SCI were likely to receive transfer training during their initial rehabilitation stay, it is possible that the use of correct handgrips and hand placement were not addressed to a sufficient degree or at all. Also for individuals with paraplegia who have intact upper-limb function, the type of handgrip used has less of an effect on their ability to perform the transfer successfully. Individuals with upper-limb weakness and involvement have to be more strategic about how to position their hands and body in order to be successful or independent with their transfers. These individuals' selfoptimized choices in movement strategies were more consistent with "best" transfer practices.

\section{Clinical Implications}

This is the first study to assess and report transfer component skill deficit rates among a large national sample of Veteran wheelchair users. The average final TAI score in our study was around 7.4 and ranged from 3.2 to 10. This average score was lower than that reported in a previous study that evaluated newly injured patients with SCI in a large university healthcare system (8.35) [22]. The differences between studies may be due to differences in the quality of transfer training provided to patients between the two healthcare systems, therapists' familiarity with best transfer practices, and the types of patients evaluated (e.g., recently injured SCI vs a mix of long-term SCI and other types of disabilities).

The ceiling effect in this study indicates that performing a perfect " 10 " is possible. In a recent study, 11 manual wheelchair users who received a TAI score less than 7.4 (the average score on the TAI based on the study) were provided $1 \mathrm{hr}$ of structured TAI-based transfer training that focused on correcting the specific skill deficits that the TAI was used to identify [48]. Not only did their TAI score improve to reach near to or at a "10," but their biomechanics also improved (e.g., peak forces and moments on the upper-limb joints were significantly reduced immediately after training). While the short-term effects are promising, longitudinal study is necessary to confirm that these results translate over time.

The results of the current study imply that there is much room for improvement in transfer skills in a Veteran population. Healthcare professionals who work with Veterans, and Veterans themselves, need to be vigilant about seeking education and training on best transfer practices. Improving access to the TAI and training materials is an important step to this process. Development of Web-based transfer training and a smartphone application for the TAI that can be widely disseminated within and outside of the VA are areas of ongoing work.

The final TAI scores in this study were not significantly different for the demographic categories analyzed (e.g., sex, types of disabilities, extent of shoulder pain). However, we did find sex-, age-, disability type-, and pain-related associations with the component skills. Thus, it is important that each TAI item be carefully examined to determine which component skills diminish the overall quality of the transfer. More emphasis should be placed on transfer education and training during the rehabilitation of women Veterans, older Veterans, and all Veterans who require wheelchairs full time and for longterm mobility.

\section{Limitations}

The subjects in this study were Veterans who were participating in a Veteran-centric recreational and sporting annual event. This group of Veterans is often perceived as having a more active lifestyle than Veteran and non-Veteran wheelchair users who do not participate in these events. While the NVWG is a competitive event, it is mainly promoted as a recreational activity that Veterans from all fitness levels can participate in. The events range from high intensity (e.g., basketball, rugby, handcycling) to low intensity (e.g., nine-ball, archery, air gun, table tennis) activities. The NDWSC is a noncompetitive event for Veterans of all abilities with activities that range from downhill skiing to snowmobiling. A comparison across studies composed of Veterans who participate in these events [49] to community-living non-Veteran manual wheelchair users [50-52] suggests that the activity levels (e.g., daily distance traveled and daily moving time) between the two groups in their usual environments are very similar. Transfer skills are also thought to be based less on activity level, strength, and agility and more on acquisition of movement skills [33]. With proper 
technique, there should be minimal muscular effort required by the individual. Indeed, if better transfer skills and being "athletic" were closely related, Veterans and non-Veterans who do not participate in organized sport and recreational events may be in greater need of transfer education and training than those who do participate. A formal investigation into the transfer skill deficit rates of nonparticipating Veterans and civilian patients is needed to extend our understanding of the effects of healthcare environments on transfer skill acquisition. Additionally, the TAI is a relatively new outcome measure, although most of the items have acceptable to high levels of reliability [27] and the validity of TAI has been extensively tested $[21,29]$.

\section{CONCLUSIONS}

Transfers are an essential activity for wheelchair users [1]. Many Veterans who were examined in this study did not perform proper transfer component skills such as setting up their body, wheelchair, and transfer environment appropriately and using proper handgrips. The associations found between certain demographic characteristics and higher skill deficit rates unveiled possible disparities in the current transfer training delivery process. Widespread dissemination of TAI and standardized transfer training methods are needed to improve transfer technique evaluations and practices across the field. This study provides a baseline reference for evaluating the effect of education and intervention on improving transfer techniques among Veterans who use wheelchairs.

\section{ACKNOWLEDGMENTS}

\author{
Author Contributions: \\ Study concept and design: A. M. Koontz, M. L. Boninger. \\ Acquisition of data: C. Y. Tsai, N. S. Hogaboom. \\ Analysis and interpretation of data: C. Y. Tsai, A. M. Koontz. \\ Drafting of manuscript: C. Y. Tsai. \\ Critical revision of manuscript for important intellectual content: \\ A. M. Koontz. \\ Statistical analysis: C. Y. Tsai, N. S. Hogaboom. \\ Obtained funding: A. M. Koontz, M. L. Boninger. \\ Study supervision: A. M. Koontz.
}

Financial Disclosures: The authors have declared that no competing interests exist.
Funding/Support: This material was based on work supported with resources and the use of facilities at the Human Engineering Research Laboratories, VA Pittsburgh Healthcare System. This project was supported by the VA Office of Research and Development, Rehabilitation Research \& Development Service (award B7149I) and by the National Institute on Disability and Rehabilitation Research, Office of Special Education and Rehabilitation Services, U.S. Department of Education (grant H133N110011).

Institutional Review: All the subjects signed a consent form approved by the VA Pittsburgh Healthcare System Institutional Review Board before testing.

Participant Follow-Up: The authors do not plan to inform participants of the publication of this study. However, participants who sign up to receive our newsletter will have access to a summary of the results.

Disclaimer: The contents of this article do not represent the views of the VA or the U.S. Government.

\section{REFERENCES}

1. Fliess-Douer O, Vanlandewijck YC, Van der Woude LH. Most essential wheeled mobility skills for daily life: An international survey among paralympic wheelchair athletes with spinal cord injury. Arch Phys Med Rehabil. 2012; 93(4):629-35. [PMID:22360975] http://dx.doi.org/10.1016/j.apmr.2011.11.017

2. Mortenson WB, Miller WC, Backman CL, Oliffe JL. Association between mobility, participation, and wheelchairrelated factors in long-term care residents who use wheelchairs as their primary means of mobility. J Am Geriatr Soc. 2012;60(7):1310-15. [PMID:22702515] http://dx.doi.org/10.1111/j.1532-5415.2012.04038.x

3. Finley MA, McQuade KJ, Rodgers MM. Scapular kinematics during transfers in manual wheelchair users with and without shoulder impingement. Clin Biomech (Bristol, Avon). 2005;20(1):32-40. [PMID:15567534] http://dx.doi.org/10.1016/j.clinbiomech.2004.06.011

4. Gagnon D, Koontz A, Mulroy S, Nawoczenski D, ButlerForslund E, Granstrom A, Nadeau S, Boninger M. Biomechanics of sitting pivot transfers among individuals with a spinal cord injury: A review of the current knowledge. Top Spinal Cord Inj Rehabil. 2009;15(2):33-58. http://dx.doi.org/10.1310/sci1502-33

5. Dalyan M, Cardenas DD, Gerard B. Upper extremity pain after spinal cord injury. Spinal Cord. 1999;37(3):191-95. [PMID:10213328] http://dx.doi.org/10.1038/sj.sc.3100802

6. Gellman H, Sie I, Waters RL. Late complications of the weight-bearing upper extremity in the paraplegic patient. Clin Orthop Relat Res. 1988;(233):132-35.

[PMID:3402118] 
7. Curtis KA, Roach KE, Applegate EB, Amar T, Benbow CS, Genecco TD, Gualano J. Development of the Wheelchair User's Shoulder Pain Index (WUSPI). Paraplegia. 1995;33(5):290-93. [PMID:7630657] http://dx.doi.org/10.1038/sc.1995.65

8. Alm M, Saraste H, Norrbrink C. Shoulder pain in persons with thoracic spinal cord injury: Prevalence and characteristics. J Rehabil Med. 2008;40(4):277-83.

[PMID:18382823] http://dx.doi.org/10.2340/16501977-0173

9. Subbarao JV, Klopfstein J, Turpin R. Prevalence and impact of wrist and shoulder pain in patients with spinal cord injury. J Spinal Cord Med. 1995;18(1):9-13. [PMID:7640974]

10. Brose SW, Boninger ML, Fullerton B, McCann T, Collinger JL, Impink BG, Dyson-Hudson TA. Shoulder ultrasound abnormalities, physical examination findings, and pain in manual wheelchair users with spinal cord injury. Arch Phys Med Rehabil. 2008;89(11):2086-93.

[PMID:18996236]

http://dx.doi.org/10.1016/j.apmr.2008.05.015

11. Goldstein B, Young J, Escobedo EM. Rotator cuff repairs in individuals with paraplegia. Am J Phys Med Rehabil. 1997;76(4):316-22. [PMID:9267192] http://dx.doi.org/10.1097/00002060-199707000-00011

12. Sie IH, Waters RL, Adkins RH, Gellman H. Upper extremity pain in the postrehabilitation spinal cord injured patient. Arch Phys Med Rehabil. 1992;73(1):44-48. [PMID:1729973]

13. Nichols PJ, Norman PA, Ennis JR. Wheelchair user's shoulder? Shoulder pain in patients with spinal cord lesions. Scand J Rehabil Med. 1979;11(1):29-32. [PMID:419395]

14. Gironda RJ, Clark ME, Neugaard B, Nelson A. Upper limb pain in a national sample of veterans with paraplegia. J Spinal Cord Med. 2004;27(2):120-27. [PMID:15162882]

15. McCasland LD, Budiman-Mak E, Weaver FM, Adams E, Miskevics S. Shoulder pain in the traumatically injured spinal cord patient: Evaluation of risk factors and function. J Clin Rheumatol. 2006;12(4):179-86. [PMID:16891921] http://dx.doi.org/10.1097/01.rhu.0000230532.54403.25

16. Pyo J, Pasquina PF, DeMarco M, Wallach R, Teodorski E, Cooper RA. Upper limb nerve entrapment syndromes in veterans with lower limb amputations. PM R. 2010;2(1): 14-22. [PMID:20129508] http://dx.doi.org/10.1016/j.pmrj.2009.10.002

17. Bostelman R, Ryu J, Chang T, Johnson J, Agrawal SK. An advanced patient lift and transfer device for the home. J Med Devices. 2010;4(1):011004. http://dx.doi.org/10.1115/1.4001255

18. Lundqvist C, Siösteen A, Blomstrand C, Lind B, Sullivan M. Spinal cord injuries. Clinical, functional, and emotional status. Spine. 1991;16(1):78-83. [PMID:2003241]

http://dx.doi.org/10.1097/00007632-199101000-00014

19. Gerhart KA, Bergstrom E, Charlifue SW, Menter RR, Whiteneck GG. Long-term spinal cord injury: Functional changes over time. Arch Phys Med Rehabil. 1993;74(10): 1030-34. [PMID:8215852] http://dx.doi.org/10.1016/0003-9993(93)90057-H

20. Nelson AL, Groer S, Palacios P, Mitchell D, Sabharwal S, Kirby RL, Gavin-Dreschnack D, Powell-Cope G. Wheelchair-related falls in veterans with spinal cord injury residing in the community: A prospective cohort study. Arch Phys Med Rehabil. 2010;91(8):1166-73.

[PMID:20684896]

http://dx.doi.org/10.1016/j.apmr.2010.05.008

21. McClure LA, Boninger ML, Ozawa H, Koontz A. Reliability and validity analysis of the transfer assessment instrument. Arch Phys Med Rehabil. 2011;92(3):499-508. [PMID:21276957] http://dx.doi.org/10.1016/j.apmr.2010.07.231

22. Rice LA, Smith I, Kelleher AR, Greenwald K, Hoelmer C, Boninger ML. Impact of the clinical practice guideline for preservation of upper limb function on transfer skills of persons with acute spinal cord injury. Arch Phys Med Rehabil. 2013;94(7):1230-46. [PMID:23537608] http://dx.doi.org/10.1016/j.apmr.2013.03.008

23. Paralyzed Veterans of America Consortium for Spinal Cord Medicine. Preservation of upper limb function following spinal cord injury: A clinical practice guideline for healthcare professionals. J Spinal Cord Med. 2005;28(5):434-70. [PMID:16869091]

24. Bromley I. Tetraplegia and paraplegia: A guide for physiotherapists. 5th ed. Edinburgh (UK): Churchill Livingstone; 1998.

25. Somer MF. Spinal cord injury: Functional rehabilitation. 2nd ed. Upper Saddle River (NJ): Prentice Hall; 2000.

26. Pierson FM. Principles and techniques of patient care. 2nd ed. Philadelphia (PA): W. B. Saunder; 1999.

27. Tsai CY, Rice LA, Hoelmer C, Boninger ML, Koontz AM. Basic psychometric properties of the transfer assessment instrument (version 3.0). Arch Phys Med Rehabil. 2013; 94(12):2456-64. [PMID:23685096] http://dx.doi.org/10.1016/j.apmr.2013.05.001

28. Williams JW Jr, Holleman DR Jr, Simel DL. Measuring shoulder function with the Shoulder Pain and Disability Index. J Rheumatol. 1995;22(4):727-32. [PMID:7791172]

29. Tsai C-Y, Hogaboom NS, Boninger ML, Koontz AM. The relationship between independent transfer skills and upper limb kinetics in wheelchair users. BioMed Research International. 2014;2014:984526. [PMID:25162039]

30. John LT, Cherian B, Babu A. Postural control and fear of falling in persons with low-level paraplegia. J Rehabil Res 
Dev. 2010;47(5):497-502. [PMID:20803393]

http://dx.doi.org/10.1682/JRRD.2009.09.0150

31. Jensen MP, Hoffman AJ, Cardenas DD. Chronic pain in individuals with spinal cord injury: A survey and longitudinal study. Spinal Cord. 2005;43(12):704-12.

[PMID:15968299]

http://dx.doi.org/10.1038/sj.sc.3101777

32. Toro ML, Koontz AM, Cooper RA. The impact of transfer setup on the performance of independent wheelchair transfers. Hum Factors. 2013;55(3):567-80. [PMID:23829031] http://dx.doi.org/10.1177/0018720812460549

33. Minkel JL, Hastings J, McClure L, Bjerkefors A. Teaching transfers-Safe and effective transfer techniques for persons with spinal cord injury. Proceedings of the 4th International Interdisciplinary Conference on Posture and Wheeled Mobility; 2010; Glasgow, UK.

34. Yanai T, Fuss FK, Fukunaga T. In vivo measurements of subacromial impingement: Substantial compression develops in abduction with large internal rotation. Clin Biomech (Bristol, Avon). 2006;21(7):692-700. [PMID:16632128] http://dx.doi.org/10.1016/j.clinbiomech.2006.03.001

35. Fattal C, Mariano-Goulart D, Thomas E, Rouays-Mabit H, Verollet C, Maimoun L. Osteoporosis in persons with spinal cord injury: The need for a targeted therapeutic education. Arch Phys Med Rehabil. 2011;92(1):59-67.

[PMID:21187206]

http://dx.doi.org/10.1016/j.apmr.2010.09.019

36. Lazo MG, Shirazi P, Sam M, Giobbie-Hurder A, Blacconiere MJ, Muppidi M. Osteoporosis and risk of fracture in men with spinal cord injury. Spinal Cord. 2001;39(4):20814. [PMID:11420736] http://dx.doi.org/10.1038/sj.sc.3101139

37. Gagnon D, Nadeau S, Noreau L, Dehail P, Gravel D. Quantification of reaction forces during sitting pivot transfers performed by individuals with spinal cord injury. J Rehabil Med. 2008;40(6):468-76. [PMID:18509563] http://dx.doi.org/10.2340/16501977-0192

38. Gagnon D, Nadeau S, Noreau L, Eng JJ, Gravel D. Electromyographic patterns of upper extremity muscles during sitting pivot transfers performed by individuals with spinal cord injury. J Electromyogr Kinesiol. 2009;19(3):509-20. [PMID:18262796] http://dx.doi.org/10.1016/j.jelekin.2007.12.005

39. Roquelaure Y, Mechali S, Dano C, Fanello S, Benetti F, Bureau D, Mariel J, Martin YH, Derriennic F, PenneauFontbonne D. Occupational and personal risk factors for carpal tunnel syndrome in industrial workers. Scand J Work Environ Health. 1997;23(5):364-69.

[PMID:9403467]

http://dx.doi.org/10.5271/sjweh.233

40. Keir PJ, Wells RP, Ranney DA, Lavery W. The effects of tendon load and posture on carpal tunnel pressure. J Hand
Surg Am. 1997;22(4):628-34. [PMID:9260617]

http://dx.doi.org/10.1016/S0363-5023(97)80119-0

41. Goodman CM, Steadman AK, Meade RA, Bodenheimer C, Thornby J, Netscher DT. Comparison of carpal canal pressure in paraplegic and nonparaplegic subjects: Clinical implications. Plast Reconstr Surg. 2001;107(6):1464-71, discussion 1472. [PMID:11335819]

http://dx.doi.org/10.1097/00006534-200105000-00024

42. Allison GT, Singer KP, Marshall RN. Transfer movement strategies of individuals with spinal cord injuries. Disabil Rehabil. 1996;18(1):35-41. [PMID:8932743]

http://dx.doi.org/10.3109/09638289609167087

43. Koontz AM, Kankipati P, Lin YS, Cooper RA, Boninger ML. Upper limb kinetic analysis of three sitting pivot wheelchair transfer techniques. Clin Biomech (Bristol, Avon). 2011;26(9):923-29.

44. Desroches G, Gagnon D, Nadeau S, Popovic M. Magnitude of forward trunk flexion influences upper limb muscular efforts and dynamic postural stability requirements during sitting pivot transfers in individuals with spinal cord injury. J Electromyogr Kinesiol. 2013;23(6):1325-33.

[PMID:24094473]

http://dx.doi.org/10.1016/j.jelekin.2013.09.003

45. Kankipati P, Boninger ML, Gagnon D, Cooper RA, Koontz AM. Upper limb joint kinetics of three sitting pivot wheelchair transfer techniques in individuals with spinal cord injury. J Spinal Cord Med. 2015;38(4):485-97.

[PMID:25130053]

http://dx.doi.org/10.1179/2045772314Y.0000000258

46. Crytzer TM, Cooper R, Jerome G, Koontz A. Identifying research needs for wheelchair transfers in the built environment. Proceedings of the RESNA 2013 Annual Conference; 2013; Seattle, WA.

47. Harvey LA, Crosbie J. Biomechanical analysis of a weightrelief maneuver in C5 and C6 quadriplegia. Arch Phys Med Rehabil. 2000;81(4):500-5. [PMID:10768543] http://dx.doi.org/10.1053/mr.2000.3788

48. Tsai CY. Biomechanical validation of transfer assessment instrument (TAI) in evaluating different independent transfers in wheelchair users [dissertation]. [Pittsburgh (PA)]: University of Pittsburgh; 2014.

49. Tolerico ML, Ding D, Cooper RA, Spaeth DM, Fitzgerald SG, Cooper R, Kelleher A, Boninger ML. Assessing mobility characteristics and activity levels of manual wheelchair users. J Rehabil Res Dev. 2007;44(4):561-71.

[PMID: 18247253]

http://dx.doi.org/10.1682/JRRD.2006.02.0017

50. Oyster ML, Karmarkar AM, Patrick M, Read MS, Nicolini $\mathrm{L}$, Boninger ML. Investigation of factors associated with manual wheelchair mobility in persons with spinal cord injury. Arch Phys Med Rehabil. 2011;92(3):484-90. 


\section{[PMID:21353831]}

http://dx.doi.org/10.1016/j.apmr.2010.09.025

51. Sonenblum SE, Sprigle S, Lopez RA. Manual wheelchair use: Bouts of mobility in everyday life. Rehabil Res Pract. 2012;2012:753165. [PMID:22848837] http://dx.doi.org/10.1155/2012/753165

52. Levy CE, Buman MP, Chow JW, Tillman MD, Fournier KA, Giacobbi P Jr. Use of power assist wheels results in increased distance traveled compared with conventional manual wheeling. Am J Phys Med Rehabil. 2010;89(8): 625-34. [PMID:20647780]

http://dx.doi.org/10.1097/PHM.0b013e3181e72286
Submitted for publication March 4, 2015. Accepted in revised form July 15, 2015.

This article and any supplementary material should be cited as follows:

Koontz AM, Tsai CY, Hogaboom NS, Boninger ML. Transfer component skill deficit rates among Veterans who use wheelchairs. J Rehabil Res Dev. 2016;53(2): 279-94.

http://dx.doi.org/10.1682/JRRD.2015.02.0023

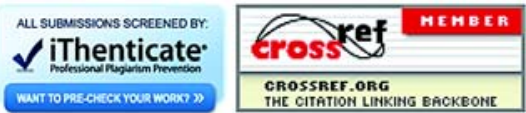


